International Journal of Medical Arts 2020; 2 [3]: 559-566.

Available online at Journal Website
https://ijma.journals.ekb.eg/
Main subject [Medicine [Obstetrics]]

Original article

\title{
Relation between Placental Thickness Measurements and Fetal Outcome in Patients with Intra- Uterine Growth Restriction [IUGR]
}

\author{
Ahmed Shahat Emam; Walaa Mohammed El-Bassioune; Abdelrahman Ali Hassan Emam; Abd Elraouf \\ Mohammad Oun
}

Department of Obstetrics and Gynecology, Damietta Faculty of Medicine, Al-Azhar University, Egypt

Corresponding author

Ahmed Shahat Emam

Email: emam78630@gmail.com

Received at: January 07, 2020; Revised at: July 04, 2020; Accepted at: July 06, 2020; Available online at: July 06, 2020

DOI: 10.21608/ijma.2020.22101.1078

\section{ABSTRACT}

Background: Placental thickness appears to be a promising parameter for estimation of gestational age of the fetus due to steady increase in placental thickness with gestational age.

Aim of the work: To investigate the relationship between placental thickness and fetal outcome in patients with intrauterine growth restriction [IUGR].

Patients and Methods: This study included patients with fetuses diagnosed clinically and by ultrasound as IUGR [estimated fetal weight $<10^{\text {th }}$ percentile for gestational age], singleton pregnancy, gestational age between $28-40$ weeks of gestation, maternal age between $20-40$ years old and body mass index between $18-30 \mathrm{~kg} / \mathrm{m}^{2}$. The placental thickness was measured at the second and third trimesters and correlated with the fetal outcome.

Results: Results revealed that, estimated fetal weight significantly increased in normal placenta when compared to either thin or thick placentae. In addition, thin placentae had significantly low fetal birth weight [1936.4 \pm 409.2$]$ when compared to thick placentae [2236.4 \pm 410.1 ] or normal placentae [2636.4 \pm 421.4$]$. Also, Apgar score was significantly higher and need for NICU admission were significantly lower with normal placentae. In addition, there is significant positive correlation between 3rd trimester placental thickness and fetal birth weight, placental weight and APGAR score.

Conclusion: Placental thickness could predict deviations from norms of birth weight in late pregnancy. It seems to be promising for estimation of gestational age of the fetus and predicting fetal outcome.

Keywords: Third trimester; Placental thickness; Birth weight; Fetal; Intrauterine growth restriction.

This is an open access article under the Creative Commons license [CC BY] [https://creativecommons.org/licenses/by/2.0/]

Please cite this article as: Emam AS, El-Bassioune WM, Emam AAH, Oun AM. Relation between Placental Thickness Measurements and Fetal Outcome in Patients with Intra Uterine Growth Restriction [IUGR]. IJMA 2020; 2[3]: 559-566.

\footnotetext{
* Main subject and any subcategories have been classified according to research topic.
} 
INTRODUCTION

Intrauterine growth restriction [IUGR] refers to fetus with marked reduction of birth weight below the tenth percentile [the lower border of normal weight] for that gestational age ${ }^{[1]}$.

IUGR is ascribed to different fetal or maternal factors and placenta is one of the important causes of growth restriction. The placental main function is to provide nutrition and oxygen to the fetus, and fetal growth to normal birth weight depends on the competent delivery of nutrients via normally functioning uteroplacental system [2]. The normal development of placenta is mandatory for normal growth of a healthy baby. At the term, the healthy baby growth is achieved by three significant factors: genetic, healthy mother and efficient uteroplacental system. Placenta is the most important factor. However, it is unfortunately often ignored [3]. Historically document normal weight of placenta at term in normal pregnancy is about $1 / 5$ of fetal weight. Both fetus and placenta are exposed to the same stress in utero life. Any maternal disease will exert its impact on the fetus and placenta. Thus, placental measurements like its thickness must reflect the status of the fetus and its outcome ${ }^{[4]}$. On the other side, any development impairment of the placenta could have a significant impact on fetal growth and outcome. The ratio of the fetal birth weight to placental weight has been used since the 1940s as an indicator for the normal fetal growth [2].

The definitive placenta could be demonstrated by ultrasound at $9-10$ gestational weeks, with a uniform granular echogenic outline. Ultrasound [US] permits placental evaluation and the detection of different placental abnormalities using different variables such as its thickness and volume [5].

Abnormal placental thickness arises the suspicion of underlying pathological process. Small placentas were found to be related to chromosomal abnormalities, chronic fetal infections, preeclampsia, diabetes \& intrauterine growth restriction [IUGR] ${ }^{[6]}$.

Several studies have reported an association between small placenta and low birth weight [LBW], and IUGR, secondary to abnormal villous development and defective fetoplacental circulation, and blood vessel formation [7].

Some pregnancies suspected of IUGR are constitutionally small but healthy; however, others fail to attain their growth potential due to factors that affect growth, such as lack of proper nourishment, chromosomal aberrations, drugs or infections. Prenatal identification of IUGR is important for improving the perinatal outcome ${ }^{[8]}$.

The hypothesis that decreased placental size precedes the onset of IUGR makes placental thickness abnormalities with the corresponding gestational age [GA], one of the early warning signs for development of IUGR]. Using two-dimensional [2D] ultrasound [US] assessment for placental size provides a safe, simple, easy, cheap, feasible and non-invasive diagnostic tool. This is more suitable in developing and low-income countries, to avoid the obstacles encountered with using three dimensional systems, being more expensive, time-consuming, and need more training ${ }^{[9]}$.

\section{AIM OF THE WORK}

The aim of this study is to investigate the association between placental thickness and fetal outcome [estimated fetal birth weight as primary outcome \& secondary outcome include birth weight, Apgar score, NICU admission] in patients with IUGR.

\section{PATIENTS AND METHODS}

The study had been conducted at Obstetrics and Gynecology Department, Al-Azhar University Hospital [New Damietta]; from May to November 2019. The study included 45 pregnant women diagnosed with intrauterine growth restriction [IUGR]. The study protocol approved by the local Institution Research Board [IRB] of faculty of medicine Al-Azhar University Damietta [ADIMIRB18032019]. In addition, an informed verbal consent had been obtained from each participant sharing in the study. Confidentiality and personal privacy had been respected in all levels of the study.

The inclusion criteria were: 1] Fetuses diagnosed as IUGR [by U/S estimated fetal weight $<10 \mathrm{th}$ percentile for gestational age as patient sure from date of LMP]; 2] Singleton pregnancy; 3] Gestational age 20 - 40 weeks of gestation; 4] Maternal age 2040 years old; 5] Body mass index [BMI] $18-30 \mathrm{~kg} / \mathrm{m}^{2}$; 6] Patient at risk [diabetes mellitus, hypertension, Preeclampsia]. On the other side, exclusion criteria were: 1] Chromosomal abnormalities; 2] Polyhydramnios; 3] Suspected placental anomaly; 4] Poor sonographic visualization of the placenta; 5] Presence of uterine or adnexal gross pathology 
The sample size calculated according to formula of Daniel [10], and frequency of intrauterine growth retardation in developing countries [3\%] according to Radon et al. [11]; and accordingly, 45 subjects were reasonable sample size.

Patients were subjected to complete history taking, thorough clinical examination, calculation of BMI, and obstetric examination. Then, ultrasound was carried out to measure placental thickness [twodimensional ultrasound; Medison ultrasound with transabdominal $3.5 \mathrm{MHz}$ probe]. The placental site had been determined in a longitudinal section using two-dimensional real-time mode. The thickness of the placental had been measured at the level of umbilical cord insertion in longitudinal course from lateral chorionic plate to the insertion of the cord apart from the retro placental area. The ultrasound determination of gestational age was determined by calculating the mean BPD, $\mathrm{HC}, \mathrm{AC}$, and FL. The thickness of the placental and gestational age was then correlated. The estimated fetal weight was calculated by the measurement of BPD, AC, and FL, using the formula proposed by Hadlock. Subsequently, the fetal outcome was evaluated and correlated with other outcome parameters of postpartum fetal weight [categorizing into groups of baby weights $<2,500$ and $>2,500 \mathrm{~g}$ ].

The technique of Transabdominal ultrasound: The sonographer uses full bladder as a 'porthole' to your uterus, so patients have to drink plenty of water before the test. patients lie supine on an examination table or bed. Gel is applied to patient's abdomen and the sonographer moves the scanner in various positions. The scan usually takes about 30 minutes. The thickness of the placental in $\mathrm{mm}$ had been measured at the level of cord insertion site. The transducer had been focused on to scan perpendicular to the chorionic and basal plates as tangential scan. The identification of the site of cord insertion by doppler was vitally significant for gaining correct measurement values.

Outcome measures of the study were:

- Primary outcome includes estimated fetal birth weight had been correlated with secondary outcome which include birth weight, Apgar score, NICU admission. An abnormal pregnancy outcome was recognized as birth weight $<$ the $10^{\text {th }}$ percentile or fetal weight $<2,500 \mathrm{~g}$. The mean values of the placental thickness along with the standard deviation were calculated for the diverse gestational ages [from the $20^{\text {th }}$ to $40^{\text {th }}$ gestational weeks].

Data management and Statistical Analysis: Data collected throughout history, examination, lab investigations and outcome measures were coded, documented and statistically analyzed using Microsoft Excel software. Data were then transferred to Statistical Package for the Social Sciences [SPSS version 20.0] software for analysis. Qualitative data represent in number and percent. But quantitative variables represented by arithmetic mean \pm SD [standard deviation]. Student [t] and Chi square tests were used to test differences for significance when appropriate. Correlation was calculated by Pearson's or Spearman's. $P$ value was set at $<0.05$ for significant results.

\section{RESULTS}

In the present study, the patient age ranged between 20 and 30 years; the mean age was $25.0 \pm 3.1$ years. Patient BMI ranged between 18.8 and $38.9 \mathrm{~kg} / \mathrm{m}^{2}$; the risk factors were in the form of gestational diabetes among 5 patients [11.1\%], gestational hypertension among 10 patients [22.2\%] and preeclampsia among 5 patients [11.1\%]. The mode of delivery was normal vaginal delivery [NVD] among 15 patients [33.3\%] and cesarean section among 30 patients [66.7\%] [Table 1].

The placental thickness at the second trimester ranged from 16.9 to 29.7 , while at the third trimester, it ranged from 27.3 to 55.1 ; the mean values were $20.82 \pm 3.169$ and $30.27 \pm 2.1$ at the second and third trimesters respectively. In addition, EFW ranged from 200 to 800 [mean value $365.54 \pm 53.48$ ] and from 1200 to 2448 [mean value $1423.62 \pm 372.08$ ] at the second and third trimesters respectively. The birth weight ranged from 2120 to $2590 \mathrm{~g}$ [mean value 2436.4 \pm 430.01 ] and APGAR ranged between 3 and 10 at first the fifth minutes, [the mean value was $6.8 \pm 1.2$, and $6.9 \pm 1.12$ at first and fifth minutes respectively] [Table 2]. Estimated fetal weight and the second and third trimester significantly increased in normal placenta when compared to either thin or thick placentae. In addition, thin placentae had significantly low fetal birth weight [1936.4 \pm 409.2$]$ when compared to thick placentae [2236.4 \pm 410.1$]$ or normal placentae [2636.4 \pm 421.4$]$. Also, Apgar score was significantly higher and need for NICU 
Emam AS, et al.

admission were significantly lower with normal placentae [Table 3]. Results of the present work indicated that, placental thickness in both second and third trimesters showed significant, moderate, proportional correlation with each of estimated fetal weight, AGAR score and fetal birth weight [Table 4].

Table [5] shows that changes in fetal weight can be predicted by placental thickness $2^{\text {nd }}$ trimester by $12.5 \%$, also changes in fetal weight can be predicted by placental thickness $3^{\text {rd }}$ trimester by $10 \%$.

Table [1]: Characteristics of the study sample size

\begin{tabular}{|c|c|c|}
\hline \multicolumn{2}{|c|}{$\begin{array}{ll}\text { Variables } \\
\end{array}$} & Statistics \\
\hline \multicolumn{2}{|c|}{ Age [years] } & $25.0 \pm 3.1 ; 20-30$ \\
\hline \multicolumn{2}{|l|}{ Weight [kg] } & $78.0 \pm 12.0 ; 55-115$ \\
\hline \multicolumn{2}{|l|}{ Height [m] } & $1.7 \pm 0.07 ; 1.55-1.78$ \\
\hline \multicolumn{2}{|l|}{$\mathrm{BMI}$} & $27.1 \pm 3.7 ; 18.8-38.9$ \\
\hline \multirow{3}{*}{$\begin{array}{l}\text { Risk } \\
\text { Factors }\end{array}$} & Gestational diabetes & $5[11.1 \%]$ \\
\hline & Gestational hypertension & $10[22.2 \%]$ \\
\hline & $\mathrm{PE}$ & $5[11.1 \%]$ \\
\hline \multirow[t]{2}{*}{ Mode of delivery } & NVD & $15[33.3 \%]$ \\
\hline & CS & $30[66.7 \%]$ \\
\hline
\end{tabular}

BMI: Body mass index; PE: preeclampsia; NVD: Normal vaginal delivery; CS: Cesarean section

Table [2]: Placental thickness, EFW, and birth weight

\begin{tabular}{|l|c|c|}
\hline \multicolumn{1}{|c|}{ Variables } & Second trimester & Third trimester \\
\hline Placental thickness & $20.82 \pm 3.169 ; 16.9-29.7$ & $30.27 \pm 2.1 ; 27.3-55.1$ \\
\hline EFW [g] & $365.54 \pm 53.48 ; 200-800$ & $1423.62 \pm 372.08 ; 1200-2448$ \\
\hline Outcome & \multicolumn{2}{|c|}{$2436.4 \pm 430.01 ; 2120-2590$} \\
\hline Birth weight [g] & \multicolumn{2}{|c|}{$6.8 \pm 1.2 ; 3-10$} \\
\hline APGAR score 1 minute & \multicolumn{2}{|c|}{$6 \pm 1.12 ; 3-10$} \\
\hline APGAR score 5 minute &
\end{tabular}

EFW: Estimated fetal weight.

Table [3]: Relation between placental thickness and outcome

\begin{tabular}{|l|c|c|c|c|c|}
\hline \multicolumn{1}{|c|}{ Placental thickness } & $\begin{array}{c}\text { Thin placenta } \\
{[\mathrm{n}=20 ; 48.9 \%]}\end{array}$ & $\begin{array}{c}\text { Normal placental thickness } \\
{[\mathrm{n}=22 ; 44.4 \%]}\end{array}$ & $\begin{array}{c}\text { Thick placenta } \\
{[\mathrm{n}=3 ; 6.7 \%]}\end{array}$ & \\
\hline Estimated Fetal weight second trimester & $360.54 \pm 53.48$ & $375.54 \pm 53.48$ & $365.54 \pm 53.48$ & 10.6 & $<0.001^{*}$ \\
\hline Estimated Fetal weight third trimester & $1745 \pm 35.82$ & $2383 \pm 23.48$ & $2076 \pm 48.52$ & 10.52 & $<0.001^{*}$ \\
\hline Fetal birth weight [g] & $1936.4 \pm 409.2$ & $2636.4 \pm 421.4$ & $2236.4 \pm 410.1$ & 10.43 & $<0.001^{*}$ \\
\hline APGAR 1 minute & $4.4 \pm 1.0$ & $9.1 \pm 0.9$ & $4.1 \pm 1.2$ & 99.9 & $<0.001^{*}$ \\
\hline APGAR 5 minute & $6.8 \pm 0.81$ & $9.1 \pm 0.91$ & $6.3 \pm 0.81$ & 30.9 & $<0.001^{*}$ \\
\hline NICU admission & $10[50.0 \%]$ & $5[22.7 \%]$ & $2[66.7 \%]$ & 7.71 & $0.033^{*}$ \\
\hline
\end{tabular}

${ }^{*}=$ Significant; $p<0.05$

Table [4]: Correlation between placental thickness and outcome

\begin{tabular}{|c|c|c|}
\hline Variable & \multicolumn{2}{|c|}{ Placental thickness [2 ${ }^{\text {nd }}$ trimester] } \\
\cline { 2 - 3 } & $\mathbf{P}$ \\
\hline Estimated Fetal weight second trimester & 0.412 & $0.031^{*}$ \\
\hline Fetal weight & 0.454 & $0.04^{*}$ \\
\hline APGAR score & 0.423 & $0.042^{*}$ \\
\hline & \multicolumn{2}{|c|}{ Placental thickness [3rd trimester] } \\
\hline Fetal birth weight & $\mathrm{r}$ & $<$ \\
\hline APGAR score & 0.319 & $<0.05^{*}$ \\
\hline
\end{tabular}

${ }^{*}=$ Significant $p<0.05$

Table [5]: Linear regression of placental thickness second and third trimesters for prediction of fetal birth weight

\begin{tabular}{|l|c|c|c|c|c|}
\hline \multicolumn{1}{|c|}{ Variable } & \multicolumn{5}{c|}{ fetal birth weight } \\
\cline { 2 - 7 } & $\mathrm{B}$ & $\mathrm{SE}$ & $\mathrm{Beta}$ & $\mathrm{p}$ & $\mathrm{R} 2$ \\
\hline Placental thickness second trimester & 51.1 & 19.5 & 0.354 & $<0.05^{*}$ & 0.125 \\
\hline Placental thickness third trimester & 36.4 & 15.6 & 0.319 & $<0.05^{*}$ & 0.10 \\
\hline
\end{tabular}

${ }^{*}=$ Significant; $p<0.05$ 


\section{DISUCSSION}

The placenta 'the sprightliness of fetus in utero' functions diversely to reinforce the maturation of the fetus and interacts with the two individuals- mother \& developing fetus. The placenta, a highly vascular fetal organ, maintains the feto-maternal circulation via its connection: the umbilical cord [7]. A normally developed placenta with efficient function is crucial for normal fetal development and growth. The size of placenta increases during fetal growth period to allow it to carry out its vital functions. If the fetal growth is compromised it is due to the abnormal functioning of the placenta which can be detected by the abnormal placental measurements [12].

Placental thickness is very much related to fetal development and may be a key in perinatal outcome. According to Sadler et al. [13], at term placenta is approximately $3 \mathrm{~cm}$ thick and measures $15-25 \mathrm{~cm}$ in diameter.

A 'warning limit' of $1.8 \mathrm{~cm}$ of placental diameter and $2 \mathrm{~cm}$ of placental thickness at 36 weeks predict low birth weight neonates. Small placentas are associated with preeclampsia, chromosomal abnormalities, severe maternal diabetes mellitus, chronic fetal infections and intrauterine growth restriction [14]. The placentas over $4 \mathrm{~cm}$ thick at term have been observed in conditions like diabetes mellitus, perinatal infections, hydrops fetalis [both immune \& non-immune]. The incidence of perinatal morbidity and mortality was considerably higher among gravida with thick placenta, related to higher rates of fetal irregularities and higher incidences of both IUGR and large for gestational age term neonates [15]. Some pregnancies suspected of IUGR are constitutionally small but healthy; however, others fail to attain their normal growth potential due to different factors, such as lack of proper nourishment, chromosomal aberrations, drugs or infections. Prenatal identification of IUGR is important for improving the perinatal outcome ${ }^{[8]}$.

The hypothesis that decreased placental size precedes the onset of IUGR, makes placental thickness abnormalities with the corresponding gestational age [GA], one of the early warning signs for development of IUGR]. Using two-dimensional [2D] ultrasound [US] assessment for placental size provides a safe, simple, easy, cheap, feasible and non-invasive diagnostic tool. This is more suitable in developing and low-income countries, to avoid the obstacles encountered with using three dimensional systems, being more expensive, time-consuming, and need more training [9].

The main objective of this study was to investigate the association between placental thickness and fetal outcome [estimated fetal birth weight as primary outcome \& secondary outcome include birth weight, Apgar score, NICU admission in patients with IUGR.

Our results are in agreement with study of Adeyekun \& Ikubor [9] as they reported that study subjects were $29.1 \pm 4.9$ years. The mean maternal weight was $71.4 \pm 13.6 \mathrm{~kg}$ and mean height was 1.6 $\pm 0.5 \mathrm{~m}$. Nagpal et al. [16] found that, mean age of their study population was $23.1 \pm 3.02$ years. Majority of women were in age group of 19-23 years.

Both fetus and the placenta exposed to the same strain during uterine life, and any maternal disease affects both placenta and fetus. Thus, placental health and measurements could reflect the health and nutritional status of the fetus and could predict pregnancy outcome. Placental thickness is the simplest measure, reflecting placental size ${ }^{[4]}$.

As regard risk factors and mode of delivery, $33.3 \%$ of cases had a normal vaginal delivery and $66.7 \%$ of cases had cesarean section. Gestational diabetes represented $11.1 \%$ of cases, Gestational hypertension represented $22.2 \%$ and preeclampsia $11.1 \%$.

Placental wellbeing and maternal health, in addition to genetically determined growth potential, are known factors that influence fetal growth. Indeed, placental disease has been shown to be the most clinically relevant of all potential underlying processes that may result in intrauterine growth restriction. Fetal weight estimation is important because birth weight has been shown to be the single most important parameter that determines neonatal survival [17].

The present study show that mean of Placental thickness 2 nd trimester was $20.5 \pm 2.5$ with range of [16.9-29.7], mean of Placental thickness 3nd trimester was $30.27 \pm 2.1$ with range of [27.3-55.1, mean of EFW [g] second trimester was 165.54 \pm 53.48 with range of [160-370], mean of EFW [g] third trimester was $1423.62 \pm 372.08$ with range of [12002448], mean Birth weight [g] was 2436.4 430.01 
with range of [2120-2590] and Mean APGAR score 1 minute 6.8 \pm 1.2 with range [3-10]. Mean APGAR6.9 \pm 1.12 score 5 minutes with range [3-10].

Our results are supported by study of Adeyekun \& Ikubor [9] as they reported that the mean values of placental thickness [PT] and EFW throughout gestation were $35.5 \pm 7.0 \mathrm{~mm}$ and $1555.0 \pm 1004 \mathrm{~g}$; respectively. Nagpal et al. ${ }^{[16]}$ reported that, at 32 and 36 weeks, mean placental thickness were $33.45 \pm$ 1.62 and $35.7 \pm 2.08 \mathrm{~mm}$ respectively.

In the current study, placental thickness $<10^{\text {th }}$ percentile was recognized as abnormally thin placentae. Also, placentae with thickness $>95^{\text {th }}$ percentile were defined as abnormally thick placentae. Placental thickness between $10^{\text {th }}$ and $95^{\text {th }}$ percentile was considered normal at 32 and 36 weeks. Mahale et al. ${ }^{[18]}$ observed that the range for thickness of placenta measured between 12-41 weeks was $1.3-3.9 \mathrm{~cm}$ and the mean placental thickness was $2.748 \mathrm{~cm}$.

A healthy full-term baby is the results of three significant factors: a healthy mother, normal genes, and good placental implantation [which considered the most important, and ignored factor] [19]. The current study shows that there is high significant relation between placental thickness second trimester and Fetal weight $2^{\text {nd }}$ trimester, also there is high significant relation between placental thickness third trimester and fetal birth weight. Our results agree with study of Afrakhteh et al. [20], as they reported that there was a significant positive correlation between placental thickness and fetal weight in the second and third trimesters [ $\mathrm{r}=0.15$, $p=0.03 ; r=0.14, p=0.04$ correspondingly]. Schwartz et al. ${ }^{[4]}$ investigated placental measurements in 1909 singleton pregnancies between 18 and 24 gestational weeks and reported that mean placental diameter and thickness were significantly smaller in small-for-gestational-age infants. Nagpal et al. [16] reported that, there was a significant correlation between placental thickness and biometric fetal parameters $[r=0.67$ and $r=0.735$ at 32 weeks and 36 weeks respectively]. In addition, there was a significant proportional correlation between placental thickness and fetal weight $[r=0.55$ and $r=0.740$ at 32 weeks and at 36 weeks successively]. Furthermore, Abu et al. [21], noted significant positive correlation between placental thickness and estimated fetal weight [EFW] in the second and third trimesters. Mahale et al. [18], reported that, the correlation coefficient between placental thickness and gestational age was found to be 0.838 and 0.916 in the second and third trimesters respectively, and significant correlation were observed between placental thickness and each of BPD and AC in the second and third trimesters respectively. Ohagwu et al. [12] conducted a study on 666 pregnancies in Nigeria. They demonstrated a significant positive correlation between placental thickness and ach of BPD and AC. They found that subnormal placental thickness for a specific gestational age may be the earliest sign of IUGR. They advocated the placental thickness measurement during usual obstetric ultrasound scan. Karthikeyan et al. [22] conducted a study on 211 women at 11-40 weeks gestations. They observed significant correlation between placental thickness and estimated fetal weight at first, second and third trimesters $[r=0.609, r=0.812$ and $r=0.814$ respectively]. They advocated the use of the placental thickness to predict gestational age. Ohagwu et al. ${ }^{[12]}$ conducted a study on 730 females. They found a fairly linear relation between gestational age and placental thickness, and obtained various regression equations to correlate placental thickness with gestational age in each trimester

In the clinical trial at our hands, $48.9 \%$ of cases had normal thickness placenta in the second trimester, $44.4 \%$ had abnormally thin and $6.7 \%$ had abnormally thick placenta. In the $3^{\text {rd }}$ trimester $48.9 \%$ of cases had normal thickness of placenta, $44.4 \%$ had abnormally thin and $6.7 \%$ had abnormally thick placenta. Our results support the BaGhel et al.[7] study and Li et al.[23]. They reported that, mean placental thickness was $24.5 \mathrm{~mm}$ at 24 weeks, 31.8 $\mathrm{mm}$ at 32 weeks and $35.5 \mathrm{~mm}$ at 36 weeks. So, the thickness of placenta in millimeters almost coincides with gestational ages. It suggests a significant positive association between placental thickness and biometric parameters at different gestational ages. Nagpal et al. [16] study demonstrated that, placental thickness $<3.0 \mathrm{~cm}$ at 32 weeks and $3.1 \mathrm{~cm}$ at 36 weeks gestations are associated with low-birthweight babies and poor fetal outcome. Comparable results were reported in the study of Habib [24]. Also, the association between placental thickness and gestational age has been reported by many researchers [25]. 
The present study shows that there is high significant relation between placental thickness second and third trimester and Apgar score at 1 minute. Also, there is statistically significant relation between placental thickness second trimester and Apgar score at $5^{\text {th }}$ minute. These results support that of Nagpal et al. [16] who reported that there was proportional correlation between placental thickness and Apgar score at 32 and 36 weeks.

The current study shows that there is significant relation between thickness of placenta second and third trimester and NICU admission. These results are comparable to Nagpal et al. ${ }^{[16]}$ who reported increased incidence of perinatal complications in fullterm neonates of low Apgar scores and increased NICU admissions in those with placental thickness $>4.0 \mathrm{~cm}$ at 36 weeks, and our study showed increased incidence of low-birth-weight babies in women with abnormally thick placenta.

The neonatal outcome was better in females with normal placental thickness than those with abnormally thin or thick placentae. This can be used to recognize the fetuses at risk by identifying women with thin placenta or thick placenta. Ahn et al. [26] reported that, the abnormal placental thickness-toestimated fetal weight ratio at 18-24 weeks gestation was associated with small-for-gestational-age infants.

In the current work, there is significant positive correlation between $2^{\text {nd }}$ trimester placental thickness and estimated fetal weight $2^{\text {nd }}$ trimester and $3^{\text {rd }}$ trimesters, fetal birth weight, and APGAR score. Changes in fetal weight can be predicted by placental thickness $2^{\text {nd }}$ trimester by $12.5 \%$ and changes in fetal weight can be predicted by placental thickness $3^{\text {rd }}$ trimester by $10 \%$. Balla et al. [27] investigated placental thickness in 53 pregnant females in their second and third trimesters. They concluded that, placental thickness $<25 \mathrm{~mm}$ in third trimester could be an indicator of IUGR and thickness $>45 \mathrm{~mm}$ might be an indicator of maternal comorbidity as diabetes and hypertension or fetal abnormalities as hydrops fetalis. Furthermore, Abu et al. [21] reported proportional correlations between placental thickness and estimated fetal weight in the second and third trimesters. Damodaram et al. [28], revealed a positive correlation, with increasing placental volume with increasing gestational age, but it was reduced in the growth-restricted fetuses. The decreased placental thickness for a gestational age may be the earliest sign of fetal growth restriction. Mathai et al. [29], reported a positive significant correlation between placental thickness and gestational age.

In short, placental thickness measured by ultrasound seems to be a promising predictor for estimation of gestational age of the fetus and predicting fetal outcome as placental thickness almost equals gestational age in weeks, placental thickness below $10^{\text {th }}$ percentile was found to be associated with low birth weight and IUGR.

\section{Financial and Non-Financial Relationships and Activities of Interest}

None

\section{REFERENCES}

1. Resnik R. Intrauterine growth restriction. Obstetr Gynecol 2002; 99:490-496. [DOI: 10.1016/ s0029-7844 [01] 01780-x].

2. Suri S, Muttukrishna S, Jauniaux E. 2D-ultrasound and endocrinologic evaluation of placentation in early pregnancy and its relationship to fetal birthweight in normal pregnancies and pre-eclampsia. Placenta 2013; 34[9]:745-50. [DOI: 0.1016/ j.placenta. 2013. 05.003].

3. Salafia CM, Zhang J, Miller RK, Charles AK, Shrout P, Sun W. Placental growth patterns affect birth weight for given placental weight. Birth Defects Res Clin Mol Teratol. 2007; 79[4]: 281-288. [DOI:10.1002/bdra. 20345].

4. Schwartz N, Wang E, Parry S. Two-dimensional sonographic placental measurements in the prediction of small for gestational age infants. Ultrasound Obstet Gynaecol. 2012; 40[6]:674-679. [DOI:10.1002/uog. 11136].

5. Chen M, Leung KY, Lee CP, Tang MH, Ho PC. Placental volume measured by three-dimensional ultrasound in the prediction of fetal alpha [0]-thalassemia: a preliminary report. Ultrasound Obstet Gynecol.2006; 28[2]:166-172. [DOI:10.1002/uog.2721].

6. Mahesh D. Sonographic evaluation of placental thickness an indicator of gestational age. J Evid Based Med Health 2016;3[11]:305-310. [DOI:10.18410/jebmh/ 2016/74].

7. Baghel P, Bahel V, Paramhans R, Sachdev P, Onkar S. Correlation of placental thickness estimated by ultrasonography with gestational age and fetal outcome. IJNMR 2015;3[3]:19-24. [ DOI: IJNMR/ 2014/13676.2057].

8. Lindqvist PG, Molin J. Does antenatal identification of small-for-gestational age fetuses significantly improve their outcome? Ultrasound Obstet Gynecol. 2005; 25: 258-64. [DOI:10.1002/uog.1806].

9. Adeyekun AA, Ikubor JE. Relationship between twodimensional ultrasound measurement of placental 
thickness and estimated fetal weight. Sahel Med. $J$ 2015;18[1]:4-7. [DOI: 10.4103/1118-8561.152151].

10. Daniel WW. Biostatistics: A Foundation for Analysis in the Health Sciences. $7^{\text {th }}$ edition. New York: John Wiley \& Sons, 1999.

11. Radon Pokracka M, Huras H, Jach R. Intrauterine growth restriction diagnosis and treatment. Przegl Lek 2015; 72[7]: 376-382. [PMID: 26817352].

12. Ohagwu CC, Oshiotse Abu P, Effiong Udoh B. Placental thickness: a sonographic indicator of gestational age in normal singleton pregnancies in Nigerian women. Internet J Med Update 2009;4[2]:9-14. [DOI: 10.4314/ ijmu.v4i2.43837].

13. Sadler T. Third month to birth. Chapter 8 , in: The fetus and placenta Lang man's Medical Embryology, 9th ed.: Lippincott Williams \& Wilkins; 9th Bk \& Cdr edition, 2004, pp 96-100.

14. Bajuri MY, Masliza WDW, Hassan MR, Naim NM, Ahmad S, Das S. Sonographically abnormal placenta: an association with an increased risk poor pregnancy outcome. La Clinica terapeutica 2017; 168[5]; e283e289. [DOI:10.7417/T.2017.2021].

15. Mesdaghi-Nia E, Behrashi M, Saeidi A, Kalahroodi MA, Sehat M. Association between PAPP-A and placental thickness. Int J Reprod BioMed. 2016; 14[6]: 421. [PMID: 27525326].

16. Nagpal K, Mittal P, Grover SB. Role of Ultrasonographic Placental Thickness in Prediction of Fetal Outcome: A Prospective Indian Study. J Obstet Gynecol India 2018; 68[5]: 349-354. [DOl:10.1007/s13224-0171038-8].

17. Baschat AA, Hecher K. Fetal growth restriction due to placental disease. Semin Perinatol. 2004; 28:67-80. [DOI: 10.1053/j.semperi.2003.10.014].

18. Mahale N, Mitra M, Mahale A, Fernandes M, Ullal S. Placental thickness and its correlation with gestational age and foetal growth parameters. Giorn It. Ost. Gin 2018; 40[1], 33-41. [DOI: 10.11138/giog/ 2018. 40.1.033.]

19. Lee AJ, Bethune M, Hiscock RJ. Placental thickness in second trimester: a pilot study to determine the normal range. J Ultrasound Med. 2012;31[2]:213-218. [DOI: 10.7863/ jum.2012.31.2.213].

20. Afrakhteh M, Moein A, Their MS, Haghighatkhah HR. Correlation between placental thickness in the second and third trimester and fetal weight. Rev Bras Ginecol Obstet. 2013; 35 [7]: 317-322. [DOI:10.1590/s010072032013000700006].
21. Abu PO, Ohagwu CC, Eze JC, Ochie K. Correlation between placental thickness and estimated fetal weight in Nigerian women. Ibrosina J Med Biomed Sci. 2009; 1:80-5. [DOI: 10.4103/1947-489X.211063].

22. Karthikeyan T, Subramaniam RK, Johnson W, Prabhu K. Placental thickness \& its correlation to gestational age \& foetal growth parameters- a cross sectional ultrasonographic study. J Clin Diagn Res. 2012; 6[10]: 1732-1735. [DOI:10.7860/JCDR/ 2012/ 4867.2652].

23. Li X, Zhou Q, Zhang M, Tian X, Zhao Y. Sonographic markers of fetal a-thalassemia major. J Ultrasound Med. 2015; 34[2]:197-206. [DOI:10.7863/ultra. 34.2.197].

24. Habib AF. Prediction of low-birth weight infants from ultrasound measurement of placental diameter and placental thickness. Ann of Saudi Med. 2002;22[56]:312-4. [DOI: 10.5144/0256-4947.2002.312].

25. Balakrishnan M, Virudachalam T. Placental thickness: a sonographic parameter for estimation of gestational age. Int J Reprod Contracept Obstet Gynaecol. 2016; 5 [12]: 4377-4381. [DOI: 10.18203/2320-1770.ijrcog 20164347].

26. Ahn KH, Lee JH, Cho GJ, Hong SC, Oh MJ, Kim HJ. Placental thickness-to-estimated foetal weight ratios and small-for-gestational-age infants at delivery. J Obstet Gynaecol. 2017; 20:1-5. [DOI:10.1080/ 01443615.2017.1312306].

27. Balla EAA, Ahmed MS, Ayad CE. Prediction of fetal growth by measuring the placental thickness using ultrasonography. J Gynecol Obstet. 2014; 2[2]:26-31. [DOI: 10.11648/ j.jgo. 20140202.14].

28. Damodaram M, Story L, Eixrach E, Patel A, McGuinness A, Allsop J, et al. Placental MRI in intrauterine fetal growth restriction. Placenta 2010; 31[6]:91-498. [DOI:10.1016/ j. placenta.2010.03.001].

29. Mathai BM, Singla SC, Nittala PP, Chakravarti RJ, Toppo JN. Placental thickness: its correlation with ultra sonographic age in normal and intrauterine growth retarded pregnancies in the late second and third trimester. J Obstet Gynaecol India. 2013; 63[4]:230-233. [DOI:10.1007/s13224-012-0316-8]. 